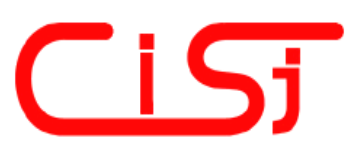

\title{
A GENETIC ALGORITHM-BASED APPROACH FOR THREE-PHASE FAULT EVALUATION IN A DISTRIBUTION NETWORK
}

\author{
Chikomborero Shambare 1), Yanxia Sun 1), OdunAyo Imoru ${ }^{2)}$ \\ 1) Department of Electrical and Electronic Engineering Science, University of Johannesburg, \\ P.O. Box 524 Auckland Park, Johannesburg, 2006, South Africa \\ Email address: chikshambare@gmail.com, ysun@uj.ac.za \\ ${ }^{2)}$ Department of Electrical and Computer Engineering, University of Namibia (JEDS Campus) \\ P.O. Box 3624, Ongwediva, Namibia. \\ Email address: aymorus@gmail.com
}

Paper history:

Received 22 November 2019

Received in revised form 11 May 2020

Accepted 08 July 2020

Available online 27 September 2020

\begin{abstract}
Standard IEC 60909 provides all the basic information that is used in the evaluation of three-phase short circuit faults. However, it uses numerous estimations in its fault evaluation procedures. It estimates voltage factors, resistance to reactance ratios $(\mathrm{R} / \mathrm{X})$, resistance to impedance ratios $(\mathrm{R} / \mathrm{Z})$ and other scaling factors. These estimates do not cater for every nominal voltage. Users often have to approximate these values. In this paper, adjustments were made to the genetic algorithm (GA) with regards to gene replacements and arrangement of scores and expectation. During fault computation, the GA was used to stochastically determine $\mathrm{R} / \mathrm{X}$ and $\mathrm{R} / \mathrm{Z}$ ratios with regards to the parameters of the power system. The GA was tested on a nominal voltage that is properly catered for by Standard IEC. The GA results and the IEC values were within an approximate range. This implies that the developed GA can be further used to determine these ratios for nominal voltages that are not sufficiently accounted for by Standard IEC. This leads to obtaining precise fault values in all instances.
\end{abstract}

Copyright (C) Research Institute for Intelligent Computer Systems, 2020.

\section{INTRODUCTION}

There is a continuously increasing demand in the energy which is generated, transmitted and distributed by modern electric power systems [1]. Identifying short-circuit faults becomes more complicated because of the corresponding increase in short-circuit power [2], and the conventional short-circuit computational methods cannot swiftly handle these short-circuit currents during abnormal operating conditions. The conventional methods for predicting, calculating and plotting short circuit faults found from the literature include [3 - 8]:

i. The Direct-Method, Per-Unit Method and Symmetric Components Technique [3, 4].

ii. Computer methods i.e. Quasi-steady-state fault analysis and Time-domain fault analysis $[5,6]$.

iii. Recent software tools e.g. ETAP (Electrical Transient Analysis Program), Easy-Power and Matlab [7, 8].
The computation of short circuit faults in the real world should consider noise and dynamic environments since they adversely affect the fault evaluation processes of all these methods. During the fault evaluation processes of the conventional methods, they try to address the problems of adaptivity to uncertain environments, parameter sensitivity, data intensity, autonomy and multiobjective optimisation $[7,9]$. However, they fail to do so sufficiently hence they do not give a wide range of operating conditions that can cope with the various time-varying configurations and parameters of the power systems networks. These conventional methods struggle with trade-off analysis for higher dimension problems. For any computational problem, they need all the characteristics of the function i.e. the task processing periods, data dependencies and synchronisation requirements before they can begin execution $[6,10]$. This means that they cannot provide a valuable mean artificial 
creativity approach and therefore this inhibits their function maximisation $[11,12]$. Evolutionary algorithms are metaheuristic tools which are a stochastic direct approach. They employ dynamic heuristics, unlike conventional methods which apply static heuristics [13]. Evolutionary algorithms begin with a population of solutions for every optimisation problem and use the Pareto sense in prioritizing the solutions [14]. Therefore, evolutionary algorithms present superior qualities in optimising complex problems. In the analytical (mathematical) modelling technique presented by this paper, a network model (of a physical situation) was created and some accompanying equations were formulated. The mathematical model was solved to see the effects of different parameters. This led to having a much more informed evaluation of the performance of the proposed methodology. The states and operating conditions that were beyond the scope of the methodology could also be noted. The rest of the paper is organised as follows. Section 2 gives the theoretical background and description of the research problems. Section 3 gives a detailed description of the proposed methodology and its accompanying motivations. Section 4 gives a detailed overview of the genetic algorithm and the proposed modifications. Section 5 presents the experimental procedures. The results are presented and discussed in Section 6. Finally, Section 7 gives the conclusion of the paper.

\section{BACKGROUND}

\subsection{CHARACTERISTICS OF FAULTS}

Three-phase short circuit faults can be classified as symmetrical three-phase faults, asymmetrical line-to-line faults, asymmetrical double line-to-earth faults and asymmetrical single line-to-earth faults $[15,16]$. Whenever a fault occurs, it divides the power system into an upstream network and a downstream network. Fig. 1 illustrates how a fault divides a network system [3].

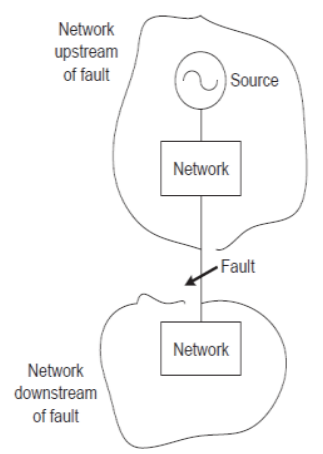

(a)

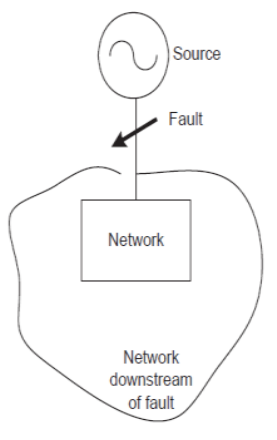

(b)
Figure 1 - Fault Characteristics [3]
In Fig. 1(a), the short circuit fault is located far from the sources (generators) and in Fig. 1(b), the fault is located at the generator terminals. For faults located far away from the sources, the effects of the parameters of the sources as rotating machines can be ignored, but for faults located at the generator terminals, the effects of the generator parameters should be taken into account $[17,18]$.

When a short circuit fault occurs close enough to the terminals of a generator, the generator will produce four components of short circuit fault. These components are the aperiodic component, the sub-transient component, the transient component and the steady-state component. Fig. 2 is an illustration of the individual components [1].

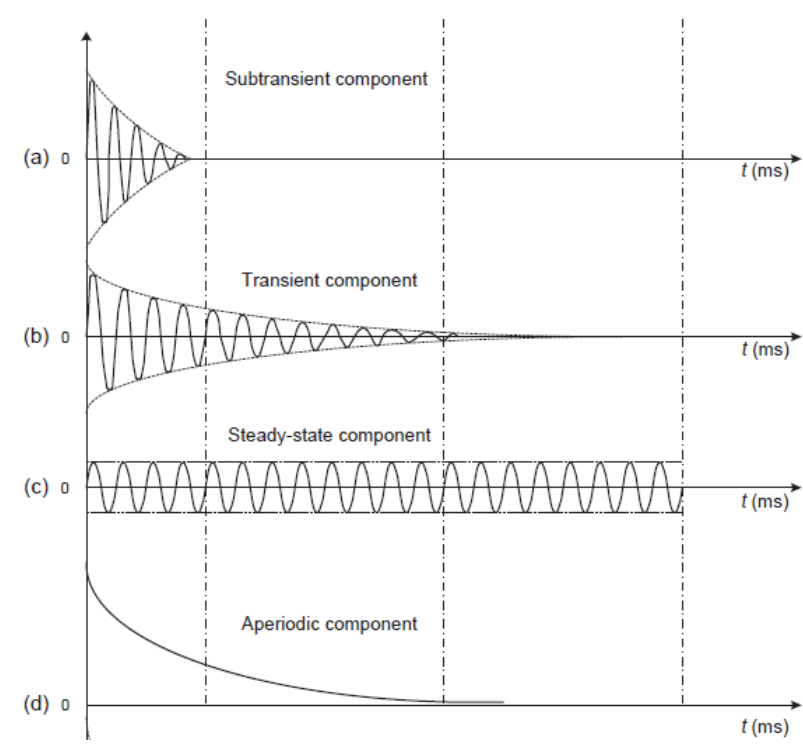

Figure 2 - Short circuit sub-components [1]

As seen in Fig. 2, these components have different decay time constants. These decaying patterns are produced as a result of the noninstantaneous change in magnetic flux in machine windings (armature windings) [19]. The four components sum up to give the full short-circuit spectrum shown in Fig. 3 [1].

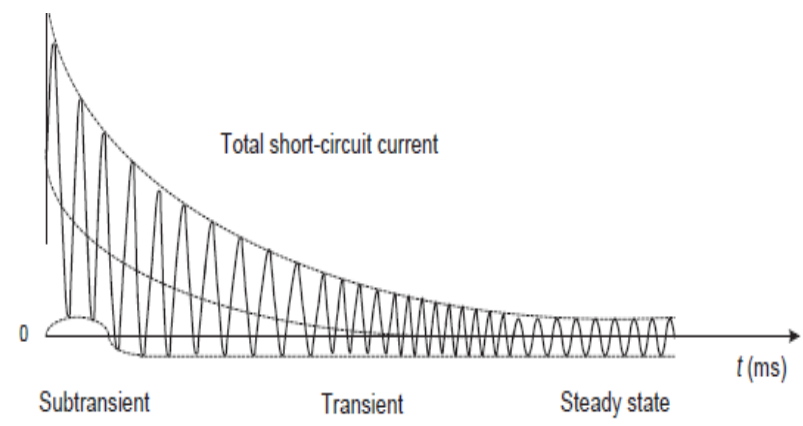

Figure 3 - Full short circuit spectrum [1] 


\subsection{REVIEW OF THE METHODS}

A power system must be able to provide reliable and continuous power flow to consumers during either normal or abnormal operating conditions. This influences the selection of a computational method based on its qualities and the properties it presents.
Table 1 presents a survey and analysis of various fault evaluation methods. Their shortcomings are laid bare and the need for employing the most advanced techniques can be seen. The information in Table 1 is given by $[1,3,5,7,11,17,20$ and 21$]$.

Table 1. Computational Methods and their Properties $[1,3,5,7,11,17,20,21]$

\begin{tabular}{|c|c|c|c|c|c|c|c|c|}
\hline & \multicolumn{8}{|c|}{ Computational Approach } \\
\hline & $\begin{array}{l}\text { Direct } \\
\text { Method }\end{array}$ & $\begin{array}{l}\text { Easy- } \\
\text { Power }\end{array}$ & ETAP & $\begin{array}{l}\text { Evolutionary } \\
\text { algorithms }\end{array}$ & $\begin{array}{l}\text { Per-Unit } \\
\text { Method }\end{array}$ & $\begin{array}{l}\text { Symmetric } \\
\text { Components }\end{array}$ & $\begin{array}{l}\text { Quasy } \\
\text { Analysis }\end{array}$ & $\begin{array}{c}\text { Time } \\
\text { domain } \\
\text { analysis }\end{array}$ \\
\hline Adaptivity & $\varnothing$ & + & + & ++ & $\varnothing$ & $\varnothing$ & $\varnothing$ & + \\
\hline Autonomy & $\varnothing$ & + & ++ & ++ & $\varnothing$ & $\varnothing$ & $\varnothing$ & + \\
\hline Convergence & + & + & + & ++ & + & + & + & + \\
\hline Heuristics & S-H & S-H & S-H & D-H & S-H & S-H & S-H & S-H \\
\hline Hybridization & $\varnothing$ & $\varnothing$ & + & ++ & $\varnothing$ & $\varnothing$ & $\varnothing$ & $\varnothing$ \\
\hline Large networks & $\varnothing$ & + & ++ & ++ & $\varnothing$ & $\varnothing$ & + & + \\
\hline Speed & + & ++ & ++ & ++ & + & + & + & ++ \\
\hline Objectivity & S-Obj & S-Obj & S-Obj & M-Obj & S-Obj & S-Obj & S-Obj & S-Obj \\
\hline Parameter Sensitivity & $\varnothing$ & $\varnothing$ & + & ++ & $\varnothing$ & $\varnothing$ & $\varnothing$ & + \\
\hline Tractability & $\varnothing$ & + & + & ++ & $\varnothing$ & $\varnothing$ & $\varnothing$ & + \\
\hline $\begin{array}{l}\text { Non-linear, non- } \\
\text { convex functions }\end{array}$ & $\varnothing$ & $\varnothing$ & $\varnothing$ & ++ & $\varnothing$ & $\varnothing$ & $\varnothing$ & $\varnothing$ \\
\hline $\begin{array}{l}\text { Non-differentiable } \\
\text { functions }\end{array}$ & $\varnothing$ & $\varnothing$ & $\varnothing$ & ++ & $\varnothing$ & $\varnothing$ & $\varnothing$ & $\varnothing$ \\
\hline $\begin{array}{l}\text { Discontinuous } \\
\text { functions }\end{array}$ & $\varnothing$ & $\varnothing$ & $\varnothing$ & ++ & $\varnothing$ & $\varnothing$ & $\varnothing$ & $\varnothing$ \\
\hline $\begin{array}{c}\text { Conceptual simplicity } \\
\text { (data intensity) }\end{array}$ & $\varnothing$ & + & + & ++ & $\varnothing$ & $\varnothing$ & $\varnothing$ & $\varnothing$ \\
\hline $\begin{array}{c}\text { Robust to noise and } \\
\text { uncertainties }\end{array}$ & $\varnothing$ & + & + & ++ & $\varnothing$ & $\varnothing$ & $\varnothing$ & + \\
\hline $\begin{array}{l}\text { Parallelism, con- } \\
\text { current computing }\end{array}$ & $\varnothing$ & $\varnothing$ & $\varnothing$ & ++ & $\varnothing$ & $\varnothing$ & $\varnothing$ & $\varnothing$ \\
\hline
\end{tabular}

Key: $\quad$ D-H $\quad-$ Dynamic Heuristics

S-Obj - Single Objective

M-Obj - Multi Objective

S-H - Static Heuristics

$++\quad-$ Excellent

$+\quad-$ Good

$\varnothing \quad-$ Poor

\subsection{RESEARCH PROBLEMS}

The computation of three-phase short circuit faults in the real world is a complex problem. In the real world, there are a lot of uncertainties and adverse conditions [19]. These negative factors interfere with any fault evaluation procedure. There 
is a strong need for deep research to seek and address the following problems in electric power distribution systems:

- The conventional methods of computing threephase short circuit faults from the point of inception are not very robust in dealing with noise and uncertainties e.g. simultaneously occurring faults or consecutive faults within a short time. They often need human intervention i.e. they lack autonomy $[1,5]$.

- Conventional methods of calculating three-phase short circuit faults are not very precise and reliable. They depend on numerous estimations in their fault evaluation processes. These estimates do not sufficiently cater for all the nominal voltages [7, 22].

- Their fault evaluation procedures are dataintensive and are not easily tractable [24].

- The precision of the conventional methods decreases with an increase in the network size. Their precision also decreases with an increase in the number of machines contributing to the fault $[25,26]$.

From the research problems highlighted above, the main objective of this paper was to develop a methodology that can sufficiently cater for every nominal voltage within $550 \mathrm{kV}$. The methodology should not depend on the predefined estimated values given by Standard IEC 60909 and IEC 61313. It should compute (stochastically determine) these values on a case-to-case basis for every optimisation case. The values should be obtained with regards to the parameters and unique specifications of the power system. During fault computation, the methodology should include non-spinning loads at various network levels. It should also include upstream reactances when computing faults at points that are far away from the sources. This leads to obtaining much more precise fault magnitudes [22].

\subsection{BENCHMARK FUNCTIONS}

Short circuit current is highly dependent on the equivalent impedance of the network seen at the fault point. The impedance value depends on the network configuration, type of system earthing, elements within the network, type of fault and the fault location [16, 17]. When a fault occurs, it is crucial to obtain the first cycle fault values i.e. the root mean square value of maximum current and magnitude of the first peak [5]. These values are for use in power system designing $[8,25]$.

Nine well-known benchmark functions were used in our experiments. The conventional methods and the genetic algorithms (GAs) were all tested on these functions. The functions are for the short circuit components, peak fault values, symmetrical three- phase fault and asymmetrical line-to-line fault. The functions are given below [15, 22, 27].

Steady-state current component ( $\left.\mathrm{I}_{\text {steady-state }}\right)$ is given by:

$$
\mathrm{I}_{\text {steady-state }}(\mathrm{t})=\frac{\mathrm{V}_{\max }}{\mathrm{X}} \cos (\mathrm{wt}+\alpha)
$$

Aperiodic current component ( $\mathrm{I}_{\text {aperiodic }}$ ) is given by:

$$
\mathrm{I}_{\text {aperiodic }}(\mathrm{t})=\frac{\mathrm{V}_{\max }}{\mathrm{X}^{\prime \prime}} \mathrm{e}^{-\mathrm{t} / \mathrm{T}} \cos (\alpha)
$$

Sub-transient current component ( $\left.\mathrm{I}_{\text {sub-transient }}\right)$ :

$\mathrm{I}_{\text {sub-transient }}(\mathrm{t})=\mathrm{V}_{\max }\left[\frac{1}{\mathrm{X}^{\prime \prime}}-\frac{1}{\mathrm{X}^{\prime}}\right] * \mathrm{e}^{-\mathrm{t} / \mathrm{T}^{\prime \prime}} \cos (\mathrm{wt}+\alpha)$

Transient current component ( $\mathrm{I}_{\text {transient }}$ ) is given by:

$$
\left.\mathrm{I}_{\text {transient }}(\mathrm{t})=\mathrm{V}_{\max }\left[\frac{1}{\mathrm{X} \prime}-\frac{1}{\mathrm{x}}\right] * \mathrm{e}^{-\mathrm{t} / \mathrm{T} \prime} \cos (\mathrm{wt}+\alpha)\right]
$$

Peak short circuit current $\left(I_{\text {peak }}\right)$ is given by:

$$
\mathrm{I}_{\text {peak }}=\mathrm{I}_{\text {fault }} * \sqrt{2} *\left(1.02+0.98 \mathrm{e}^{-\frac{3 \mathrm{R}}{\mathrm{x}}}\right)
$$

Symmetrical three-phase fault:

$$
\mathrm{I}_{3 \text {-phase }}=\frac{\mathrm{V}_{\mathrm{ph}} / \sqrt{3}}{\mathrm{Z}_{\mathrm{sc}}}
$$

Line-to-line fault:

$$
\mathrm{I}_{\text {line-line }}=\frac{\mathrm{V}_{\mathrm{ph}}}{2 * \mathrm{Z}_{\mathrm{sc}}}
$$

Line-to-line fault:

$$
\mathrm{I}_{\text {line-line }}=\frac{\sqrt{3}}{2} * \mathrm{I}_{3-\text { phase }}
$$

The impedance at any fault point is given by:

$$
Z_{s c}=\sqrt{R^{2}+X^{2}}
$$

From the equations above, $\mathrm{X}^{\prime \prime}$ is sub-transient reactance. $\quad X^{\prime}$ is transient reactance, $X$ is synchronous reactance, $T^{\prime \prime}$ is sub-transient time constant, $\mathrm{T}^{\prime}$ is transient time constant, $\mathrm{T}$ is aperiodic time constant, $V_{\max }$ is maximum phase voltage at source terminals, $Z_{\mathrm{sc}}$ is the equivalent impedance seen at the fault point, $I_{\text {fault }}$ is normal fault current, $\mathrm{V}_{\mathrm{ph}}$ is the phase to neutral voltage $\left(\mathrm{V}_{\mathrm{ph}}\right.$ is generally less than $\mathrm{V}_{\max }$ especially on the step-down side of the transformers) and $\alpha$ is the switching angle. 


\section{METHODOLOGY}

For distribution sub-systems, the resistances (R) are normally much smaller than the reactances $(\mathrm{X})$. The resistances and reactances make up the impedance (Z) [1]. Standard IEC 60909 gives the $\mathrm{R} / \mathrm{X}$ and $\mathrm{R} / \mathrm{Z}$ values for networks below $550 \mathrm{kV}$ nominal voltage. The $\mathrm{R} / \mathrm{Z}$ ratios will always be a value between 0.1 and 0.3 and the $\mathrm{R} / \mathrm{X}$ ratios vary depending on the network configuration but they are generally in the range of 0.1 to 1 [5]. These values are approximated depending on the source voltage of the network. The details for computing short circuit faults based on Standard IEC 60909 are given below $[17,22,27]$.

When $\sum X$ is the sum of reactances and $\sum R$ is the sum of resistances, short circuit impedance $Z_{\mathrm{sc}}$ is given by:

$$
\mathrm{Z}_{\mathrm{sc}}=\sqrt{\left(\sum R\right)^{2}+\left(\sum X\right)^{2}} .
$$

Here, we define:

$$
\begin{aligned}
\mathrm{X}_{\text {up-stream }} & =\text { up-stream reactance } \\
\mathrm{R}_{\text {up-stream }} & =\text { up-stream resistance } \\
\mathrm{Z}_{\text {up-stream }} & =\text { up-stream impedance }
\end{aligned}
$$

For high voltage systems, Standard IEC 60909 states that a user can estimate upstream resistances from the following relationships (ratios):

$$
\begin{gathered}
\text { At } 150 \mathrm{kV} \rightarrow \frac{\mathrm{R}_{\text {up-stream }}}{\mathrm{Z}_{\text {up-stream }}} \approx 0.1 \\
\mathrm{R}_{\text {up-stream }} \approx 0.1 * \mathrm{Z}_{\text {up-stream }} \\
\text { At } 20 \mathrm{kV} \rightarrow \frac{\mathrm{R}_{\text {up-stream }}}{\mathrm{Z}_{\text {up-stream }}} \approx 0.2 \\
\mathrm{R}_{\text {up-stream }} \approx 0.2 * \mathrm{Z}_{\text {up-stream }} \\
\text { At } 6 \mathrm{kV} \rightarrow \frac{\mathrm{R}_{\text {up-stream }}}{\mathrm{Z}_{\text {up-stream }}} \approx 0.3 \\
\mathrm{R}_{\text {up-stream }} \approx 0.3 * \mathrm{Z}_{\text {up-stream }}
\end{gathered}
$$

Reactances can be obtained from (10) as follows:

$$
\mathrm{X}_{\text {up-stream }}=\sqrt{\left(\mathrm{Z}_{\text {up-stream }}\right)^{2}-\left(\mathrm{R}_{\text {up-stream }}\right)^{2}}
$$

The relationship between reactance and impedance in (14) can be simplified to:

$$
\mathrm{X}_{\text {up-stream }}=\left[\sqrt{1-\left(\frac{\mathrm{R}_{\text {up-stream }}}{\mathrm{Z}_{\text {up-stream }}}\right)^{2}}\right] * \mathrm{Z}_{\text {up-stream }}
$$

When $\mathrm{R} / \mathrm{X}$ is small, in the order of 0.1 to 0.2 for low-voltage networks and 0.05 to 0.1 for mediumvoltage networks, Standard IEC 60909, IEC 60034 and IEC 60076 highlight that the following estimations can be used $[3,17]$ :

$$
\begin{aligned}
\mathrm{R}_{\text {Generators }} & \approx 0.1 * \mathrm{X}_{\text {Generators }} \\
\mathrm{R}_{\text {Motors }} \approx 0.2 * \mathrm{X}_{\text {Motors }} & \\
\mathrm{X}_{\text {Transformers }} & \approx \mathrm{Z}_{\text {Transformers }} \\
\mathrm{R}_{\text {Transformers }} & \approx 0.2 * \mathrm{X}_{\text {Transformers }}
\end{aligned}
$$

\subsection{IMPLEMENTATION OF THE TOOLS}

During fault computation, the total impedance at any fault point constitutes of:

- The up-stream resistances and reactances.

- The resistances and the reactances of all the other components at that particular fault point i.e. cables, breakers and bus-bars.

Two main tools were used to compute fault values for evaluations and analysis i.e. the conventional methods and the modified genetic algorithms. The algorithms were implemented within Matlab. Matlab M-Script Files were used for implementing the genetic algorithms. There were Matlab M-Script Files also written for implementing the conventional methods.

\subsubsection{CONVENTIONAL METHODS}

The first computational method was the use of the conventional methods i.e. the Symmetric components technique and the Direct-Method. The conventional methods computed fault values entirely based on the steps from Standard IEC 60909 and IEC 61313. The ratios for resistance to impedance that were substituted into (15) were obtained from the approximations given in (11) to (13) by Standard IEC 60909. There was a need for proper application of correct voltage factors and impedance correction factors [24]. Proper implementation of these factors increases simplicity and technical accuracy during the fault evaluation processes of the conventional methods [2].

\subsubsection{GENETIC ALGORITHMS}

The second computational method was the use of modified genetic algorithms. From the IEC coefficients given in (11) to (13), some nominal voltages are not properly accounted for, e.g. if a 
power system is of $85 \mathrm{kV}$ nominal voltage, it is difficult for the designer to choose between (11) and (12). This adversely impacts all the other values that will be obtained using (15). Also when nominal voltages go over $200 \mathrm{kV}$, there are no precise IEC ratios that a user can depend on. This influenced the development of the proposed computational approach that was used by the genetic algorithms.

Here, the GAs computed fault values by recalculating impedances at each fault location taking into account fault point impedances and upstream reactances. They computed fault values based on (10). The coefficient values that can be seen in (11) to (13) were determined stochastically with regards to the parameters and unique specifications of the optimised network. To supplement the abovementioned procedures, Fig. 5 in Section 5 gives more explicit details of the GAs fault evaluation procedures.

\section{MODIFIED GENETIC ALGORITHM}

The genetic algorithm searches for solutions based on the principles of natural selection [30]. The genetic algorithm works as a multipath algorithm, searching multiple peaks simultaneously and in parallel, thereby decreasing the risk of trapping in local minima [31]. It functions by developing codes for the values and evaluates the fitness of every string. The genetic algorithm uses Pareto sense and does not require any derivatives or other auxiliary knowledge. The genetic algorithm functions by exploring search spaces where the probability of finding optimum performance is highest $[13,29]$. It can autonomously schedule, prioritise and balance an optimisation problem.

Regardless of its good qualities, the genetic algorithm has some weaknesses. One of the main weaknesses of the genetic algorithm is premature convergence [29]. The chief cause of this is the loss of diversity. If population diversity can be achieved throughout the optimisation procedures, the search path will become much better [21]. Trapping into a suboptimal solution will also be avoided [28]. Mutation is one of the key mechanisms that ensure and maintain diversity. Perfect mutation is needed to avoid the loss of genetic material. When crossover does not guarantee access to all the desired search spaces, random gene changes through mutation will assist in providing variations in the population [31].

The above-mentioned weaknesses led to modifications in the mutation, selection, creation and fitness scaling functions. The details of the proposed enhancements that were implemented and their motivations are given below.

\subsection{CREATION FUNCTION}

The genetic algorithm has two in-built creation options which are creation 'uniform' and creation 'linear-feasible'. These in-built functions do not give satisfactory and explicit options with regards to altering and making amendments to some parameters [7]. We proposed changes to the creation uniform function to address two main defects that are not properly accounted for by the in-built functions i.e.

- To continuously influence the number of individuals that can be created at each evolution stage.

- To create a sufficient initial population for constrained cases.

Since the genetic algorithm works as a multipath search algorithm, the above-mentioned changes would ensure search efficiency until termination of the optimisation processes [21]. This would greatly decrease the chances of local minima trapping [31]. This would also help the algorithm to effectively explore all the search spaces where the probability of finding optimum solutions is highest [29].

For the first impediment, subsequent individuals in our proposed function were created with regards to the total population (totPop) and the initial population provided (In_P). Two variables were created and added to help in making the adjustments. The adjustments were implemented as follows:

IndividualsToBeCreated $=\beta *($ totPop $-\Psi)$

$$
\begin{aligned}
& \Theta \in[0 ; \text { infinity }] \\
& \Psi \in[0 ;
\end{aligned}
$$

For the second impediment, adjustments to the range of values (used in creating the initial populations when considering bounds and constraints) would bring the desired effects when creating the array of populations. It was implemented as follows:

$$
\begin{gathered}
\text { range }=\phi * \text { (options. PopInitRange) } \\
\phi \in[0 ; \text { infinity }]
\end{gathered}
$$

The magnitude of $\phi$ directly affected the selection of $\beta$ and $\Psi$ because the subscripted assignment dimensions of IndividualsToBeCreated should not mismatch the Population arrays. The optimum values were $\phi=4, \beta=1$ and $\Psi=0$.

\subsection{FITNESS SCALING FUNCTION}

In this function, the best candidates would be given the same opportunities to reproduce. We 
proposed the use of a variable $(\eta)$. This variable would help in controlling the relationship between scores, expectation and the number of parents. $\eta$ determines the amount of expectation with regards to the population size. By trial and error, an optimum value between 0 and 1 could be determined. This value selects the optimum number of scores for the parents at any particular stage during the evolution cycles.

The scores would go on to be arranged in descending order to ensure that the top scores were given priority in influencing expectation. This eliminated the use of probabilities that are commonly used in the in-built functions [30].

$$
\begin{gathered}
\eta=\operatorname{ceil}(\text { length }(\text { scores }) * \eta) \\
{[\sim, \mathrm{i}]=\operatorname{sort}\left(\text { scores, }{ }^{\prime}\right. \text { descend') }}
\end{gathered}
$$

The strength of the proposed fitness function is that regardless of when raw scores are not in a good range, the best scores will still have precedence. Another advantage is that there is no stalling during optimisation when there is a degenerate scenario i.e. when some of the scores have equal magnitudes. Stalling is a big problem for fitness scaling functions that use probabilities when assigning scores and arranging expectations [7]. Another advantage of the proposed function is that there will be no negative expectations since $\eta$ was a value between 0 and 1 .

This gives the proposed scaling function much better qualities over the in-built scaling functions which do not sufficiently cater for all possible operating scenarios e.g. shift-linear fitness scaling has problems with the survival rates of individuals, proportional and rank fitness scaling have problems when raw scores are not in a good range [12]. Top fitness scaling has problems in choosing the best quantity of scores for parents whilst it also does not have optimum default values for higher dimension instances [14].

\subsection{SELECTION FUNCTION}

The proposed selection function would sort expectation (exp) in descending order by:

$$
\exp =\operatorname{sort}\left(\exp (:, 1),{ }^{\prime} \operatorname{descend}\right)^{\prime}
$$

By sorting expectation in descending order, the top parents are selected for crossover and mutation. This gives the best parents top priority and eliminates the use of probabilities and random sampling which are common in the in-built functions [21]. The parents were also limited to the interval between 1 and the population size.

By trial and error, this function proved useful and better for the actual evolution of higher-performing individuals.

\subsection{MUTATION FUNCTION}

In this proposed mutation function, the genes that are mutated are equally spread throughout the genes' range. The probability of a genome being mutated was controlled with the aid of a variable $(\lambda)$ in the range 0 to 1 . By trial and error, values of $\lambda$ in the range of 0.05 to 0.20 proved to give optimum results when all the other optional parameters had been set.

Secondly, a gene had to be replaced by a value randomly chosen from a guided range. The bigger the range implies more diversity since the probability of replacing a gene with a value (similar structure) that has already replaced another gene will be small. This ensures maximum diversity. Variable ' $\alpha$ ' was created and used for implementing that. Where ' $\mathrm{mp}$ ' is the mutation points;

$$
\begin{gathered}
\mathrm{mp}=\operatorname{find}(\operatorname{rand}(1, \text { length }(\text { child }))<\lambda) \\
\text { range }=\alpha *(\text { range }(:, \mathrm{mp})) \\
\alpha \in[0 ; \text { infinity }]
\end{gathered}
$$

The optimum value of $\alpha$ was 8 . Bigger values of $\alpha$ increased optimisation time without showing any significant improvement in the results.

Based on the value of 'range' above, another variable ' $\gamma$ ' was created and it was used to control the mutation process in the creation of children by the following procedures:

$$
\begin{gathered}
A=\operatorname{range}(1,:) \\
B=\operatorname{range}(2,:) \\
\text { spread }=\gamma *(B-A) \\
\gamma \in[0 ; \text { infinity }]
\end{gathered}
$$

The optimum value of $\gamma$ was 4 with bigger values of $\gamma$ not suitable since this was constrained optimisation. The value of 'spread' would go on to be used as follows:

$$
\operatorname{child}(\mathrm{mp})=\mathrm{A}+\operatorname{rand}(1, \text { length }(\mathrm{mp})) * \operatorname{spread}(30)
$$

$$
\text { Mutation_Children (i,: ) = child }
$$

\subsection{PARAMETER SETTINGS OF THE GA}

The traditional genetic algorithm without the proposed enhancements will use the reference GA; the genetic algorithm that has been modified to supplement some defects will use the reference MGA. For the optimisation problem in this research, hybrid functions that could be added since the optimisation procedure had bounds (as constraints) are patternsearch and fmincon. These minimisation functions run after the genetic algorithm terminates 
and retain a more accurate solution. MGAP will be MGA with the patternsearch minimisation algorithm. MGAF will be MGA with the fmincon minimisation algorithm.

Therefore, four different genetic algorithms (GAs) would be tested on the fitness functions evaluated in this research i.e. GA, MGA, MGAF and MGAP. Table 2 gives the genetic algorithm parameters. Some parameters in Table 2 could be varied adaptively to suit the custom functions and the minimisation functions.

Table 2. Parameters of the Genetic Algorithms

\begin{tabular}{|c|c|}
\hline Parameter & Setting \\
\hline Creation function & Enhanced (modified) \\
\hline Crossover function & Intermediate, 0.6 \\
\hline Population type \& size & Double vector; 1000 \\
\hline Initial population range & {$[-10 ; 10]$} \\
\hline Pareto fraction & 0.4 \\
\hline Selection function & Enhanced (modified) \\
\hline Penalty factor & 100 \\
\hline Initial penalty & 10 \\
\hline Migration fraction & 0.2 \\
\hline Migration interval & 20 \\
\hline Fitness scaling function & Enhanced (modified) \\
\hline Migration direction & Both \\
\hline Mutation function & Enhanced (modified) \\
\hline Stall test & Geometric weighted \\
\hline Stall time limit & 60 \\
\hline Hybrid functions & Fmincon \& Patternsearch \\
\hline Non-linear solver & Augmented Lagrangian \\
\hline
\end{tabular}

\subsection{TESTING OF THE ALGORITHMS}

The GA, MGA, MGAF and MGAP were first tested on a standard benchmark function. This was done to confirm their robustness and accuracy. The Rastrigin function was used as the test function. All the algorithms were run 5 times and their results are presented in Table 3. The Rastrigin function is given below:

$$
\begin{gathered}
f(\mathrm{x})=20+\mathrm{X}_{1}^{2}+\mathrm{X}_{2}{ }^{2}-10\left(\cos 2 \pi \mathrm{X}_{1}+\cos 2 \pi \mathrm{X}_{2}\right) \\
\mathrm{Xi} \in[-5.12,5.12]
\end{gathered}
$$

Table 3. GA results on the Rastrigin Function

\begin{tabular}{|c|c|c|c|c|c|}
\cline { 2 - 6 } \multicolumn{1}{c|}{} & 1 & 2 & 3 & 4 & 5 \\
\cline { 2 - 6 } \multicolumn{1}{c|}{} & {$\left[\mathrm{x}_{1} ; \mathrm{x}_{2}\right]$} & {$\left[\mathrm{x}_{1} ; \mathrm{x}_{2}\right]$} & {$\left[\mathrm{x}_{1} ; \mathrm{x}_{2}\right]$} & {$\left[\mathrm{x}_{1} ; \mathrm{x}_{2}\right]$} & {$\left[\mathrm{x}_{1} ; \mathrm{x}_{2}\right]$} \\
\hline GA & {$[0 ; 0]$} & {$[0 ; 1.99]$} & {$[-1 ; 0]$} & {$[0 ; 0]$} & {$[0 ; 0.74]$} \\
\hline MGA & {$[0 ; 1.5]$} & {$[0 ; 0]$} & $\begin{array}{c}{[0 ;} \\
0]\end{array}$ & {$[0 ; 0]$} & {$[0 ; 0]$} \\
\hline MGAF & {$[0 ; 0]$} & {$[0.21 ; 1]$} & {$[0 ; 0]$} & {$[-1 ; 0]$} & {$[0 ; 0]$} \\
\hline MGAP & {$[0 ; 0]$} & {$[0 ;-0.4]$} & {$[0 ; 0]$} & {$[0 ; 0]$} & {$[0 ; 0]$} \\
\hline
\end{tabular}

The Rastrigin function given in (32) has a global minimum of $[0 ; 0]$. From Table 3 , it can be seen that GA struggles with retaining the global minima. It sometimes converges to local minima. In optimisation cases, an algorithm that converges poorly and settles to local minima is regarded as inaccurate and unreliable [21, 31]. That particular algorithm must not be given much priority with regards to optimising much more sophisticated problems [13]. Henceforth, GA was discarded and not used for our experimental procedures.

\section{EXPERIMENTAL PROCEDURES}

The model of the network used in this work was created based on $[3,18,19]$. The model resembles a real-world system. It has all the basic components of a power system as well as some protection devices i.e. the main power supply, backup sources, transformers, synchronous machines, isolators, circuit breakers, relays, switches, earthing gears and loads. The algorithms/methods highlighted in Section 3 would all be tested on the model for their robustness on the research problems highlighted in Section 2.

\subsection{EXPERIMENTAL MODEL}

The network that is given in Fig. 4 has a $20 \mathrm{kV}$ source that supplies a high-voltage/low-voltage substation via a $1 \mathrm{~km}$ overhead line. Two $2000 \mathrm{kVA}$ generators also supply as back-up power to the main source. The generators supply the substation busbars in parallel to the main source. Parallel connected transformers of equal magnitude $1250 \mathrm{kVA}$ supply the low-voltage busbars. The lowvoltage busbars supply feeders which go to 3 motors rated $100 \mathrm{~kW}$ each. When the fault occurs, all the motors are running. All connection cables are identical. Symmetrical three-phase short circuit fault and asymmetrical line-to-line fault clear of earth should be calculated at:

- Point $\mathrm{W}$ i.e. at the high-voltage bus-bars

- Point X i.e. 15 meters from the transformer on the low-voltage bus-bars

- Point Y i.e. on the low-voltage subdistribution board bus-bars

- Point $\mathrm{Z}$ i.e. motor terminals

- Reverse currents of all the motors at the busbars should also be computed. 


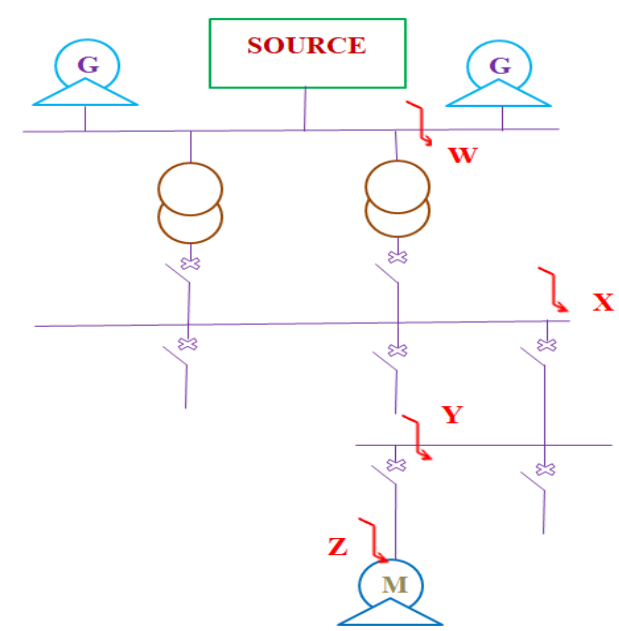

Figure 4 - Line Diagram of the Optimised Network

The parameter details in full are as follows:

Generators $\quad 2000 \mathrm{kVA}, \mathrm{X}_{\text {subtransient }}=20 \%$

Transformers

$1250 \mathrm{kVA}, \mathrm{U}_{\mathrm{sc}}=5.5 \%$,

Secondary winding $220 / 410 \mathrm{~V}$

Motors

$100 \mathrm{~kW}, \mathrm{X}=20 \%, \cos \emptyset=0.85$

Efficiency $=0.9$

Source

Overhead lines

$\mathrm{U}=20 \mathrm{kV}, \mathrm{S}_{\mathrm{sc}}=500 \mathrm{MVA}$

Main LV switchboard

$1 \mathrm{~km}, 100 \mathrm{~mm}^{2}$

3 bars, 15 meters, $400 \mathrm{~mm}^{2} / \mathrm{ph}$

Sub-distribution board 3 single-core cables, $100 \mathrm{~m}, 400 \mathrm{~mm}^{2}$

Feeder cables

3 single-core cables

$50 \mathrm{~m}, 50 \mathrm{~mm}^{2}$

\subsection{COMPUTATIONAL PROCEDURES}

\subsubsection{CONVENTIONAL METHODS}

The network has a $20 \mathrm{kV}$ source and it can be derived from (12) that the ratio of resistance to impedance will be 0.2 . Therefore:

$$
\mathrm{R}_{\text {up-stream }}=0.2 * \mathrm{Z}_{\text {up-stream }}
$$

Substituting 0.2 into (15) will give:

$$
\mathrm{X}_{\text {up-stream }}=0.98 * \mathrm{Z}_{\text {up-stream }}
$$

Therefore from (33) and (34), it can be derived that:

$$
\begin{gathered}
\mathrm{R}_{\text {up-stream }} \approx 0.2 * \mathrm{Z}_{\text {up-stream }} \\
\approx 0.2 * \mathrm{X}_{\text {up-stream }} \\
\frac{\mathrm{R}_{\text {up-stream }}}{\mathrm{X}_{\text {up-stream }}} \approx 0.2
\end{gathered}
$$

From the given parameters about the power system, $\mathrm{Z}_{\text {up-stream }}$ can be obtained from:

$$
\mathrm{Z}_{\text {up-stream }}=\frac{U^{2}}{S_{S c}}
$$

Equations (33) to (35) assist the conventional methods in obtaining the reactances, resistances and impedances at the labelled fault points. For fault at point $\mathrm{W}$, the source voltage is divided by the obtained impedances to get the fault current. Points $\mathrm{X}, \mathrm{Y}$ and $\mathrm{Z}$ are on the low-voltage side of the transformers. The stepped-down voltages are used when computing their fault currents [1].

\subsubsection{GENETIC ALGORITHMS (MGA, MGAF, MGAP)}

To eliminate stochastic discrepancies, each algorithm was repeated 20 times at each fault point. From (11) to (19) and (33) to (35), all the ratios from the Standard IEC 60909 with regards to this power system have values that are between 0 and 1 . Therefore, all the search bounds of the three genetic algorithms used in this experiment would be varied adaptively within the range of lower-bound $=0$ and upper-bound $=1$. This is because the scalar quantities that we were determining stochastically must have an 'absolute value' that is greater than 0 but less than or equal to $1[5,21]$.

\subsubsection{GAs OPTIMISATION PROCEDURE}

\subsubsection{GAs AT FAULT-POINT W}

Using Fig. 4, the first step was to use (15) to obtain the value of $X_{\text {up-stream }}$ from $Z_{\text {up-stream. The value }}$ of $Z_{\text {up-stream }}$ was obtained using (36). After obtaining the value of $Z_{\text {up-stream }}$, the GAs would not go on to use the Standard IEC 60909 coefficients that are given in (33) to (35) to obtain the value of $\mathrm{X}_{\text {up-stream. }}$ Instead, the coefficient was left as an unknown value within the objective function and was determined stochastically using the procedures in Fig. 5. The next step was to obtain $R_{\text {up-stream }}$ from the computed values of $X_{\text {up-stream }}$ and $Z_{\text {up-stream. The GAs used (35) in }}$ which they had to stochastically determine the coefficient. There was also a need to obtain the value of $R_{\text {Generators }}$ from the value of $\mathrm{X}_{\text {Generators. }}$ The value of $\mathrm{X}_{\text {Generators }}$ was computed from the given parameters about the power system. To obtain the value of $\mathrm{R}_{\text {Generators, }}$, the GAs did not go on to use the $\mathrm{R} / \mathrm{X}$ coefficient that is given in (16) but the coefficient was also determined stochastically using the procedures in Fig. 5.

\subsubsection{GAs AT FAULT-POINTS X, Y, Z}

For faults at $\mathrm{X}, \mathrm{Y}$ and $\mathrm{Z}$ in Fig. 4, the reactances and the resistances are cumulative values i.e. they are made up of fault point values and up-stream values. However, at Point $\mathrm{X}$, there was a need to 
obtain the value of $X_{\text {Transformers }}$ from the value of $\mathrm{Z}_{\text {Transformers. }}$ The obtained value of $\mathrm{X}_{\text {Transformers }}$ was further used to get the value of $\mathrm{R}_{\text {Transformers. }}$ Based on Fig. 5, the given R/X value in (19) was determined stochastically when computing the value of $\mathrm{R}_{\text {Transformers. }}$

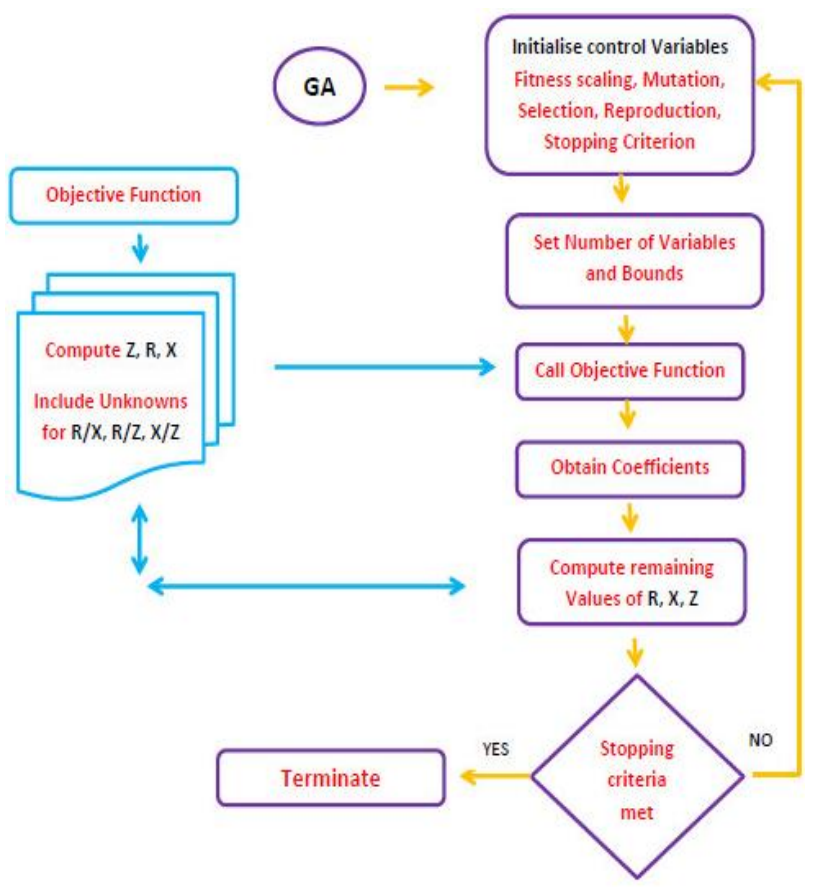

Figure 5 - GA Fault Evaluation Procedures

\section{RESULTS}

\subsection{THE COMPUTED COEFFICIENTS}

Fig. 5 and Section 5 give all the details and steps that were used by the GAs in obtaining the coefficient values that are given in Tables 4 to 6 . Tables 4 to 6 give the coefficient values that were obtained by all the genetic algorithms (MGA, MGAF and MGAP) in 20 runs. Standard IEC values are also included in the tables for comparison.

From the tables, when all the GA coefficients are rounded off to one decimal place, they will be equal to the IEC coefficient values. This makes all the proposed genetic algorithms capable of handling the computational problem that was being investigated. An analysis is made below as to which ones are the most suitable.

Table 4. Comparison between MGA and IEC Coefficients

\begin{tabular}{|c|c|c|c|c|c|}
\hline Equation & $\begin{array}{c}\text { Min } \\
\text { value }\end{array}$ & $\begin{array}{c}\text { Max } \\
\text { value }\end{array}$ & $\begin{array}{c}\text { Average } \\
\text { for 20 } \\
\text { runs }\end{array}$ & $\begin{array}{c}\text { IEC } \\
\text { value }\end{array}$ & $\begin{array}{c}\% \\
\text { Dev }\end{array}$ \\
\hline$(16)$ & 0.0006 & 0.24 & 0.102 & 0.1 & $2 \%$ \\
\hline$(19)$ & 0.186 & 0.192 & 0.192 & 0.2 & $4 \%$ \\
\hline$(34)$ & 0.73 & 1 & 0.995 & 0.98 & $1.5 \%$ \\
\hline$(35)$ & 0.039 & 0.64 & 0.206 & 0.2 & $3 \%$ \\
\hline
\end{tabular}

Table 5. Comparison between MGAP and IEC Coefficients

\begin{tabular}{|c|c|c|c|c|c|}
\hline Equation & $\begin{array}{c}\text { Min } \\
\text { value }\end{array}$ & $\begin{array}{c}\text { Max } \\
\text { value }\end{array}$ & $\begin{array}{c}\text { Average } \\
\text { for 20 } \\
\text { runs }\end{array}$ & $\begin{array}{c}\text { IEC } \\
\text { value }\end{array}$ & $\begin{array}{c}\% \\
\text { Dev }\end{array}$ \\
\hline$(16)$ & 0.0081 & 0.19 & 0.0965 & 0.1 & $3.5 \%$ \\
\hline$(19)$ & 0.192 & 0.192 & 0.192 & 0.2 & $4 \%$ \\
\hline$(34)$ & 0.91 & 1 & 0.968 & 0.98 & $1.2 \%$ \\
\hline$(35)$ & 0.063 & 0.48 & 0.194 & 0.2 & $3 \%$ \\
\hline
\end{tabular}

Table 6. Comparison between MGAF and IEC Coefficients

\begin{tabular}{|c|c|c|c|c|c|}
\hline Equation & $\begin{array}{c}\text { Min } \\
\text { value }\end{array}$ & $\begin{array}{c}\text { Max } \\
\text { value }\end{array}$ & $\begin{array}{c}\text { Average } \\
\text { for 20 } \\
\text { runs }\end{array}$ & $\begin{array}{c}\text { IEC } \\
\text { value }\end{array}$ & $\%$ Dev \\
\hline$(16)$ & 0.014 & 0.247 & 0.086 & 0.1 & $14 \%$ \\
\hline$(19)$ & 0.006 & 0.192 & 0.192 & 0.2 & $4 \%$ \\
\hline$(34)$ & 0.65 & 1 & 0.89 & 0.98 & $9.18 \%$ \\
\hline$(35)$ & 0.094 & 0.301 & 0.163 & 0.2 & $18.5 \%$ \\
\hline
\end{tabular}

The coefficient values that the MGA and MGAP obtained are within an approximate range. This is because the convergence points of these algorithms were almost the same. The MGAF obtained values that deviate a lot more from those obtained by the other algorithms thus implicating that it struggled with convergence to the global minima.

However, the coefficients obtained by all the GAs are slightly different from the values given by the Standard IEC 60909. The MGA and MGAP coefficients deviate from the IEC values by not more than $4 \%$ whilst the MGAF coefficients deviate by up to $18.5 \%$. This makes the former two to be the much better GA options for the computational problem that was being investigated. Fig. 6 is a plot of the optimisation tools against their maximum percentage deviation from the predefined IEC values. The trends in Fig. 6 explicitly show the best and worst algorithms when computing coefficient values.

When running the algorithms to obtain the coefficient values, the average time per run was noted and it has been plotted in Fig. 7.

The MGA and MGAP converged at a lesser number of iterations, thus their computational time was short. Computational time is a key element used when evaluating an algorithm. The algorithms were evaluated using Matlab R2017a software installed on an Acer Aspire with Intel(R) Celeron(R) processor at $1.80 \mathrm{GHz}$ and $4.00 \mathrm{~GB}$ Ram with Windows 10 Pro operating system. 


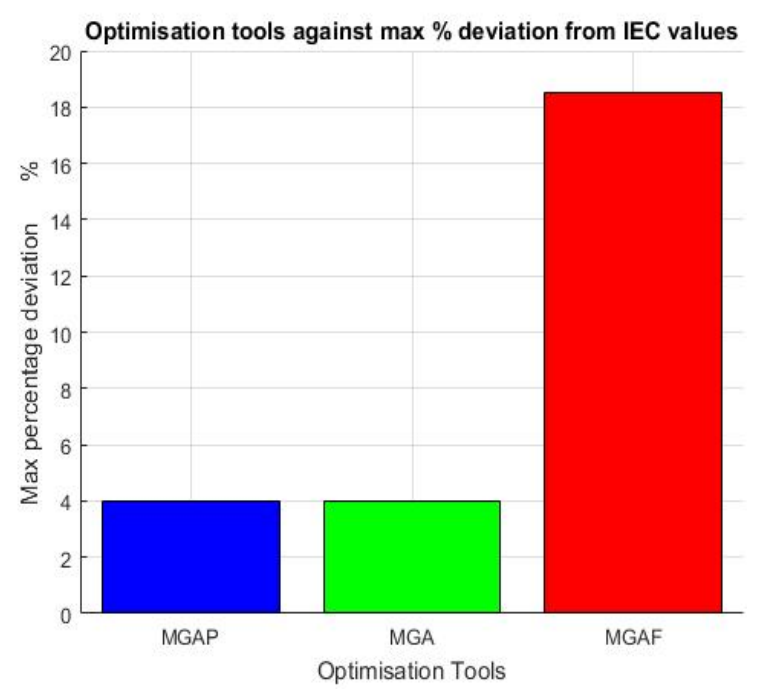

Figure 6 - GA tools plotted against $\max \%$ deviations

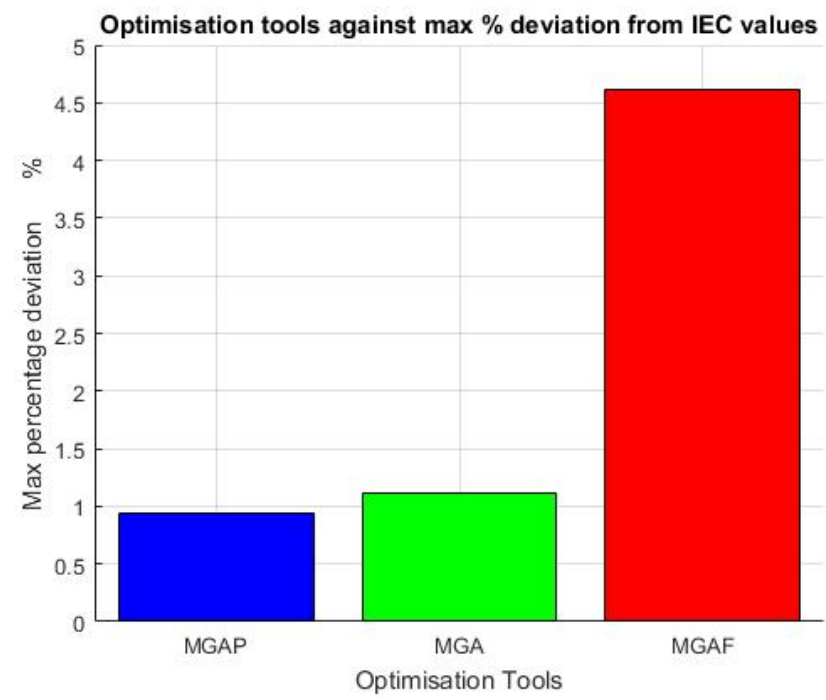

Figure 7 - GA tools average computational time

Moreover, when doing the runs, 18 or more times, the MGA and MGAP algorithms would obtain a value that is almost equal or equal to the IEC given values. This gives the two algorithms a 'confidence interval' greater than $90 \%$ when searching for coefficients. This makes these two algorithms to be more reliable since they quickly attain stable and precise results and go on to consistently converge at the same point. This cements these two as the best performing and most suitable algorithms for the computational problem.

\subsection{THE COMPUTED IMPEDANCES}

Tables 7 to 9 give the fault point impedances that were obtained by all the GAs and conventional methods (CMs). The impedances that were obtained using the GAs computed coefficients were almost equal to the impedances that the CMs obtained using
IEC coefficients. This is because the coefficients that were used by the GAs and CMs were within an approximate range.

Table 7. Comparison between MGA and CM Impedances

\begin{tabular}{|c|c|c|c|c|}
\hline $\begin{array}{c}\text { Fault } \\
\text { Point }\end{array}$ & $\begin{array}{c}\text { MGA } \\
\text { value }\end{array}$ & CM value & Difference & $\begin{array}{c}\% \\
\text { Dev }\end{array}$ \\
\hline $\mathrm{W}$ & $1.095 \Omega$ & $1.082 \Omega$ & $0.013 \Omega$ & $1.0 \%$ \\
\hline $\mathrm{X}$ & $7.695 \mathrm{~m} \Omega$ & $8.010 \mathrm{~m} \Omega$ & $0.315 \mathrm{~m} \Omega$ & $3.9 \%$ \\
\hline $\mathrm{Y}$ & $25.037 \mathrm{~m} \Omega$ & $25.411 \mathrm{~m} \Omega$ & $0.374 \mathrm{~m} \Omega$ & $1.47 \%$ \\
\hline $\mathrm{Z}$ & $51.353 \mathrm{~m} \Omega$ & $51.757 \mathrm{~m} \Omega$ & $0.404 \mathrm{~m} \Omega$ & $0.78 \%$ \\
\hline
\end{tabular}

Table 8. Comparison between MGAP \& CM

\begin{tabular}{|c|c|c|c|c|}
\hline $\begin{array}{c}\text { Fault } \\
\text { Point }\end{array}$ & $\begin{array}{c}\text { MGAP } \\
\text { value }\end{array}$ & CM value & Difference & $\begin{array}{c}\% \\
\text { Dev }\end{array}$ \\
\hline $\mathrm{W}$ & $1.073 \Omega$ & $1.082 \Omega$ & $0.009 \Omega$ & $0.83 \%$ \\
\hline $\mathrm{X}$ & $7.685 \mathrm{~m} \Omega$ & $8.010 \mathrm{~m} \Omega$ & $0.325 \mathrm{~m} \Omega$ & $4.06 \%$ \\
\hline $\mathrm{Y}$ & $25.026 \mathrm{~m} \Omega$ & $25.411 \mathrm{~m} \Omega$ & $0.385 \mathrm{~m} \Omega$ & $1.52 \%$ \\
\hline $\mathrm{Z}$ & $51.342 \mathrm{~m} \Omega$ & $51.757 \mathrm{~m} \Omega$ & $0.415 \mathrm{~m} \Omega$ & $0.80 \%$ \\
\hline
\end{tabular}

Table 9. Comparison between MGAF \& CM

\begin{tabular}{|c|c|c|c|c|}
\hline $\begin{array}{c}\text { Fault } \\
\text { Point }\end{array}$ & $\begin{array}{c}\text { MGAP } \\
\text { value }\end{array}$ & CM value & Difference & $\begin{array}{c}\% \\
\text { Dev }\end{array}$ \\
\hline $\mathrm{W}$ & $1.019 \Omega$ & $1.082 \Omega$ & $0.063 \Omega$ & $5.82 \%$ \\
\hline $\mathrm{X}$ & $7.659 \mathrm{~m} \Omega$ & $8.010 \mathrm{~m} \Omega$ & $0.351 \mathrm{~m} \Omega$ & $4.38 \%$ \\
\hline $\mathrm{Y}$ & $25.0 \mathrm{~m} \Omega$ & $25.411 \mathrm{~m} \Omega$ & $0.411 \mathrm{~m} \Omega$ & $1.62 \%$ \\
\hline $\mathrm{Z}$ & $51.323 \mathrm{~m} \Omega$ & $51.757 \mathrm{~m} \Omega$ & $0.434 \mathrm{~m} \Omega$ & $0.83 \%$ \\
\hline
\end{tabular}

From Tables 7 to 9, disregarding MGAF which has the most abnormal deviations stated in Section 6.1 , for faults at the source terminals and faults at the load terminals i.e. at points $\mathrm{W}$ and $\mathrm{Z}$ in Fig. 4, there was a small difference in the obtained values of impedance between the CMs and the GAs. The percentage deviations between GAs and CMs impedance values are all less than $1 \%$ and $0.8 \%$ at points $\mathrm{W}$ and $\mathrm{Z}$ respectively. For faults on the lowvoltage busbars and low-voltage subdistribution board i.e. at points $\mathrm{X}$ and $\mathrm{Y}$ which are distant enough from the rotating machines, the difference in the obtained values is significant. The percentage deviation between GAs and CMs values at point $X$ is around $4 \%$ and at point $\mathrm{Y}$ it is around $1.5 \%$. CMs give much larger impedance values.

A large impedance value means that when that impedance value is substituted into Kirchhoff's 
voltage and current laws, a small value of short circuit current will be obtained. Fig. 8 is the plot of asymmetrical three-phase line-to-line currents that were computed using the impedances from the GAs and CMs. The trends for the computed symmetrical and asymmetrical three-phase currents are the same. The only difference is in their fault current magnitudes.

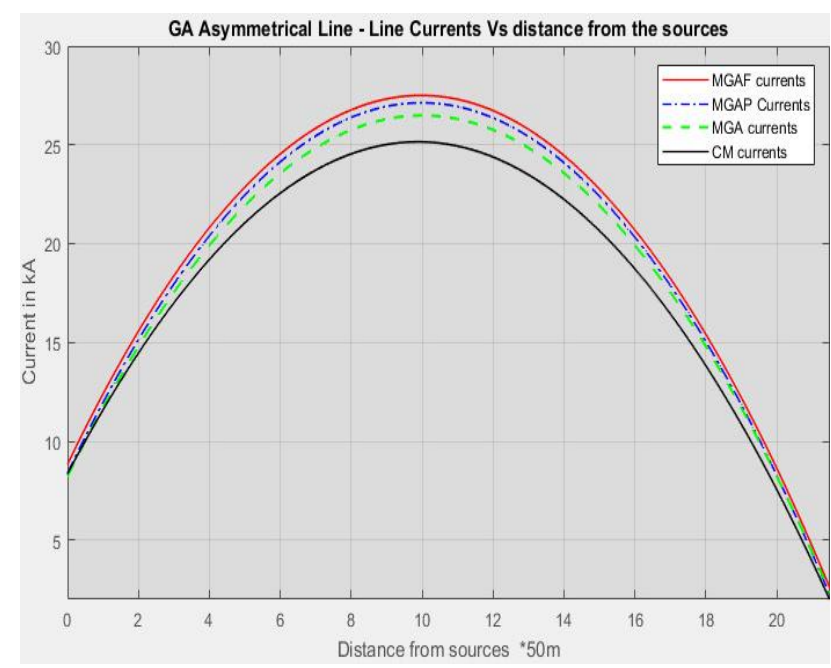

Figure 8 - Computed fault currents

Fig. 8 clearly shows the sections of the power system that the CMs do not properly account for. This means that for faults on busbars and subdistribution boards, the CMs fault evaluation procedures tend to understate the magnitude of short circuit current. This is dangerous, especially in the setting of protection devices.

Standard IEC 60909 tries to rectify this problem but fails to do so sufficiently. The Standard IEC 60909 states that for faults at points far away from the sources where there is a considerable effect of spinning loads e.g. motors $[1,5,16]$

- It is easier for conventional methods to "estimate conservatively' the fault currents than to calculate the equivalent impedances $[1,16]$.

- Currents by motors at these points can be calculated using the 'motor + cable' total impedance or the current can be estimated using starting motor current $\left(\mathrm{I}_{\text {start }}\right)$ and rated current of a generator $\left(\mathrm{I}_{\mathrm{r}}\right)[5,16]$.

$$
\frac{\mathrm{I}_{\mathrm{start}}}{\mathrm{I}_{\mathrm{r}}} * \text { rated motor current }
$$

The estimates used by the CMs, from Standard IEC 60909, provide 'conservative protection' current values. Nonetheless, these fault values are not the precise fault magnitudes such as the ones that can be obtained by the GAs at any network level.

\subsection{THE COMPUTED CURRENTS}

Table 10 contains the computed symmetrical three-phase fault currents and Table 11 gives the computed asymmetrical three-phase line-to-line currents.

Table 10. Symmetrical three-phase fault currents in

\begin{tabular}{|c|c|c|c|c|}
\cline { 2 - 5 } \multicolumn{1}{c|}{} & $\mathrm{W}$ & $\mathrm{X}$ & $\mathrm{Y}$ & $\mathrm{Z}$ \\
\cline { 2 - 5 } \multicolumn{1}{c|}{} & $\mathrm{I}_{3 \mathrm{P}}$ & $\mathrm{I}_{3 \mathrm{P}}$ & $\mathrm{I}_{3 \mathrm{P}}$ & $\mathrm{I}_{3 \mathrm{P}}$ \\
\hline $\mathrm{RMC}$ & 0.185 & 2.583 & 2.432 & 4.876 \\
\hline $\mathrm{CM}$ & 10.674 & 32.535 & 12.128 & 10.203 \\
\hline MGA & 10.545 & 33.745 & 12.263 & 10.240 \\
\hline MGAP & 10.761 & 33.785 & 12.267 & 10.241 \\
\hline MGAF & 11.331 & 33.889 & 12.276 & 10.242 \\
\hline
\end{tabular}

Table 11. Asymmetrical line-line fault currents in kA

\begin{tabular}{|c|c|c|c|c|}
\cline { 2 - 5 } \multicolumn{1}{c|}{} & $\mathrm{W}$ & $\mathrm{X}$ & $\mathrm{Y}$ & $\mathrm{Z}$ \\
\cline { 2 - 5 } \multicolumn{1}{c|}{} & $\mathrm{I}_{\mathrm{LL}}$ & $\mathrm{I}_{\mathrm{LL}}$ & $\mathrm{I}_{\mathrm{LL}}$ & $\mathrm{I}_{\mathrm{LL}}$ \\
\hline $\mathrm{RMC}$ & 0.185 & 2.583 & 2.432 & 4.876 \\
\hline $\mathrm{CM}$ & 9.244 & 28.175 & 10.503 & 8.836 \\
\hline MGA & 9.132 & 29.223 & 10.620 & 8.868 \\
\hline MGAP & 9.319 & 29.258 & 10.623 & 8.869 \\
\hline MGAF & 9.813 & 29.348 & 10.631 & 8.870 \\
\hline
\end{tabular}

$\mathrm{I}_{3 \mathrm{P}}$ is the symmetrical three-phase fault, $\mathrm{I}_{\mathrm{LL}}$ is the asymmetrical three-phase line-to-line fault; $\mathrm{CM}$ is the conventional methods and RMC are the reverse motor currents.

In this research, two fault conditions were computed i.e. symmetrical three-phase faults and asymmetrical three-phase line-to-line faults. The symmetrical three-phase fault was computed because it is generally considered that symmetrical three-phase faults induce the highest fault currents. Its investigation is necessary because it plays a key role in equipment selection (equipment with the highest electrodynamic and current withstand capability) $[16,17]$. The asymmetrical three-phase line-to-line fault was computed to check if the proposed methodology applied to asymmetrical three-phase short circuit faults.

There are some slight differences between the GAs results and the CMs results. The reasons for the small discrepancies in the obtained values are:

- The R/X and $R / Z$ values used by the GAs are slightly different from the $\mathrm{R} / \mathrm{X}$ and $\mathrm{R} / \mathrm{Z}$ values 
used by the CMs (CMs strictly used values given by the Standard IEC 60909, IEC 61313, IEC 60034 and IEC 60076).

- In computing impedances, the GAs fault evaluation procedures included all the components and their base properties e.g. nonspinning loads, circuit breakers and isolators, unlike CMs which consider some of the components to have negligible resistances e.g. protection devices [7].

- At point X i.e. the main low voltage switchboard busbars, the resistances and the reactances are recalculated for the low voltage network. The conventional methods calculations do not account for the high voltage upstream reactance to that of the parallel-connected transformers, busbars and cables at that fault point [2].

- At all the fault points, the conventional methods only include the immediate up-stream reactances and resistances e.g. at point $\mathrm{Y}$ conventional methods only include the resistances and the reactances from Point $\mathrm{X}$ and at Point $\mathrm{Z}$ they only include values from Point $\mathrm{Y}$ [5]. The GAs include the total upstream reactances and resistances in their computational processes i.e. they do not neglect the sources and their parameters for faults far away from the sources.

Nonetheless, the results obtained from the proposed methodology of using GAs and the results from the CMs based on the Standard IEC 60909 (alongside IEC, 61313, IEC 60034 and IEC 60076) are very similar and within an approximate range. Protection units that can be selected using values obtained from either of the methods would be the same [5, 32]. This means that the proposed methodology can be successfully used for the computation of three-phase short circuit faults. The successful optimisation of a practical network example demonstrated in Section 4 highlights the strength and diverse applicability of GAs to power systems' computational problems.

The advantages of using GAs and the proposed computational procedures are:

- Unique Optimisation: The computational procedures/algorithms optimise power systems with regards to their unique specifications i.e. they do not rely on the IEC estimated coefficients or use Equation (37). This means that the procedures can be reliably used for the evaluation of any nominal voltage within $550 \mathrm{kV}$ $[15,16]$.

- Precise fault magnitudes: The computational procedures give more precise fault magnitudes because unlike conventional methods (CMs),

- They take all components into consideration and do not ignore some of their base properties. CMs ignore non- spinning loads and protection devices $[3,6,33]$.

○ They also include the effects of sources when computing faults far away from sources [5, 18].

- Enhanced modifications: When using the proposed computational procedures, GAs can be modified and enhanced with regards to the desired precision level and complexity of the problem [21, 29].

- Choose specifications: During fault evaluation, the user can specify the optimisation bounds and there can also be fitness scaling of the functions $[14,34]$.

\section{CONCLUSIONS}

Standard IEC 60909 and IEC 61313 layout all the short circuit fault evaluation procedures. However, in their methodologies, they use a lot of estimations. The commonly used estimates are $\mathrm{R} / \mathrm{X}$ and $\mathrm{R} / \mathrm{Z}$ ratios. During fault evaluation, these ratios play a key role in determining the upstream and fault point impedances. The IEC lays out these ratios over a wide range and does not sufficiently cater for every nominal voltage within $550 \mathrm{kV}$. When the need arises, the user has to estimate these values accordingly. In this paper, modified genetic algorithms were developed and used to stochastically determine these ratios during fault evaluation.

One of the objectives of this research was to minimise the weaknesses of the genetic algorithm before using it for fault evaluation. Some adjustments were made to the traditional GA to reduce premature convergence, loss of population diversity and trapping into suboptimal solutions. Meticulous parameter selection was also implemented and Fmincon and Patternsearch minimisation functions were added to improve the algorithm. This resulted in the development of 3 algorithms i.e. MGA, MGAF and MGAP.

The 3 algorithms were initially tested on a benchmark function i.e. the Rastrigin function. The proposed modelling of the algorithms and the conscientious parameter selection proved to improve the algorithms significantly. The obtained results on the benchmark test function showed that the proposed algorithms were much more robust, fast, efficient, reliable and accurate as compared to the traditional GA.

A model of a power system with nominal voltages within a range that is well catered for by the IEC was developed and optimised. The GAs managed to obtain coefficient values that were within an approximate range to the IEC values. MGA and MGAP coefficients deviated by less than 
4\% from the IEC values. This resulted in their impedances deviating by less than $4 \%$ from the CMs impedances. Moreover, in determining the $\mathrm{R} / \mathrm{X}$ and $\mathrm{R} / \mathrm{Z}$ values, the MGA and MGAP runs had a 'confidence interval' greater than $90 \%$. The threephase fault currents that the GAs went on to obtain were similar to the fault currents that were obtained by the CMs, with the GAs results arguably much better because of their efficacious and dependable fault evaluation procedures.

This implies that if the methodology could give comparable results to $\mathrm{CMs}$ within the well-defined ranges, the proposed methodology can reliably still go on to sufficiently satisfy nominal voltage regions that are not well catered for by $\mathrm{CMs}$ and the Standard IEC. GAs can sufficiently sustain any nominal voltage because the proposed methodology optimises power systems on a case-to-case basis with regards to the parameters and unique specifications of a power system.

The developed methodology was tested for its robustness in dealing with uncertainties during fault computation. Its precision and reliability when there is an increase in the number of machines contributing to the fault current was tested. Regardless of the uncertainties, the GAs would still produce results within an approximate range to those produced by the CMs. The successful computation and evaluation of the network in Section 5 shows that GAs can support both small and large networks of the radial distribution sub-systems. This means that GAs can also support the ring and the meshed distribution sub-systems since they are derivatives of the radial distribution sub-system. Henceforth, GAs can be successfully used for the complex problem of computing three-phase short circuit faults for any nominal voltage within $550 \mathrm{kV}$.

\section{ACKNOWLEDGEMENTS}

This research is supported partially by South African National Research Foundation Grants (No. 112108 and 112142), and South African National Research Foundation Incentive Grant (No. 95687), Eskom Tertiary Education Support Program, and Research grant from URC of University of Johannesburg.

\section{REFERENCES}

[1] J. C. Das, Short-Circuit in AC and DC Systems ANSI, IEEE and IEC Standards, CRC Press, Boca Raton, 2017.

[2] S. Osowski, and R. Salat, "Fault location in transmission line using hybrid neural network," COMPEL - The International Journal for Computation and Mathematics in Electrical and Electronic Engineering, vol. 21, issue 1, pp. 18-30, 2002. https://doi.org/10.1108/ 03321640210410715

[3] O. P. Malik, and A. A. Sallam, Electric Distribution Systems, New Jersey: John Wiley \& Sons, 2011.

[4] K. Dębowski, and M. Pasko, "Symmetrization of asymmetrical nonlinear three-phase load supplied from non-ideal sinusoidal voltage source," COMPEL - The International Journal for Computation and Mathematics in Electrical and Electronic Engineering, vol. 28, issue 3, pp. 512-522, 2009. https://doi.org/10.1108/ 03321640910940819

[5] N. Tleis, Power Systems Modelling and Fault Analysis Theory and Practice, Elsevier, Oxford, 2008.

[6] M. Sarlak, and S.M. Shahrtash, "SVM-based method for high-impedance faults detection in distribution networks," COMPEL - The International Journal for Computation and Mathematics in Electrical and Electronic Engineering, vol. 30, issue 2, pp. 431-450, 2011. https://doi.org/10.1108/03321641111 101014

[7] J. Zhu, Optimization of Power System Operation, Second Edition, IEEE Press, John Wiley \& Sons, New Jersey, NJ, 2015.

[8] A. Bakshi, and S.V. Kulkarni, "Towards short-circuit proof design of power transformers," COMPEL - The International Journal for Computation and Mathematics in Electrical and Electronic Engineering, vol. 31, issue 2, pp. 692-702, 2012. https://doi.org/10.1108/03321641211200662

[9] G. Cvetkovski, L. Petkovska, and P. Lefley, "Optimal design of single phase permanent magnet brushless DC motor using particle swarm optimisation," COMPEL - The International Journal for Computation and Mathematics in Electrical and Electronic Engineering, vol. 33, issue 6, pp. 1863-1876, 2014. https://doi.org/10.1108/COMPEL-112013-0379

[10] S. Leva, and A.P. Morando, "Lossy three-phase transmission line transient analysis by Park approach," COMPEL - The International Journal for Computation and Mathematics in Electrical and Electronic Engineering, vol. 24 issue 3, pp. 1041-1060, 2005. https://doi.org/10.1108/03321640510571237

[11] O. Imoru, M. A. Bhaskar, A. A. G. Jimoh, and Y. Haman, "Diagnosis of stator shorted-turn faults in induction machines using discrete wavelet transform," African Journal of Science, Technology, Innovation and Development, vol. 9, issue 3, pp. 349-355, 2017. https://doi.org/ $10.1080 / 20421338.2017 .1327933$ 
[12] S. O. Obadan, and Z. Wang, "A hybrid optimization approach for complex nonlinear objective functions," International Journal of Computing, vol. 17, issue 2, pp. 102-112, 2018.

[13] H. Fan, "A modification to particle swarm optimization algorithm," Engineering Computations, vol. 19, issue 8, pp. 970-989, 2002, https://doi.org/10.1108/02644400210 450378

[14] L. Sahoo, A.K. Bhunia, and D. Roy, "Reliability optimization in stochastic domain via genetic algorithm," International Journal of Quality \& Reliability Management, vol. 31, issue 6, pp. 698-717, 2014. https://doi.org/10.1108/IJQRM-06-2011-0090

[15] J. C. Das, Power System Analysis - ShortCircuit Load Flow and Harmonics, Second Edition, CRC Press, Boca Raton, 2016.

[16] IEC 60909-0, Short-Circuit Currents in ThreePhase a.c. Systems. Calculation of Currents International Standard, 2001.

[17] IEC 60909-0, Short-Circuit Currents in ThreePhase a.c. Systems. Calculation of Currents International Standard, 2016.

[18] A. Mathur, V. Pant, and B. Das, "Unsymmetrical short-circuit analysis for distribution system considering loads," International Journal of Electrical Power and Energy Systems, vol. 70, issue 1, pp. 27-38, 2015.

[19] F. B. Costa, et al., "Real-time detection of transients induced by high-impedance faults based on boundary wavelet transform," IEEE Trans. Industry Applications, vol. 51, issue 1, pp. 5312-5323, 2015.

[20] H. W. Lim, and N. A. M. Isa, "Particle swarm optimization with increasing topology connectivity," Engineering Applications of Artificial Intelligence, vol. 27, issue 1, pp. 80102, 2014.

[21] P. Ghamisi, and J. A. Benediktsson, "Feature selection based on hybridization of genetic algorithm and particle swarm optimization," IEEE Geoscience and Remote Sensing Letters, vol. 12, issue 2, pp. 303-313, 2015.

[22] J.C. Das, Power System Analysis Short-Circuit Load Flow and Harmonics, Second Edition, CRC Press, Georgia, 2012.

[23] T.Z.E. Benhacine, A. Nesba, S. Mekhtoub, and R. Ibtiouen, "A new approach for steady state analysis of three-phase SEIG feeding singlephase load," COMPEL - The International Journal for Computation and Mathematics in Electrical and Electronic Engineering, vol. 38, issue 1, pp. 46-67, 2019. https://doi.org/10.1108/COMPEL-11-20170474
[24] A. Campoccia, E.R. Sanseverino, and G. Zizzo, "A mathematical approach for studying interconnected earthing systems inside MV networks," COMPEL - The International Journal for Computation and Mathematics in Electrical and Electronic Engineering, vol. 26, issue 5, pp. 1364-1391, 2007. https://doi.org/ 10.1108/03321640710823064

[25] E. N. Juszczak, and M. Radzik, "The FEM Analysis of Non-symmetrical Short Circuit Forces and Fields in the Window of Convertor Transformer," COMPEL - The International Journal for Computation and Mathematics in Electrical and Electronic Engineering, vol. 11, issue 1, pp. 213-216, 1992. https://doi.org/10. 1108/eb051790

[26] E.R. Sanseverino, A. Campoccia, M.L. Di Silvestre, and G. Zizzo, "A simple unsynchronized two-end algorithm for faults location and identification in electrical distribution systems," COMPEL - The International Journal for Computation and Mathematics in Electrical and Electronic Engineering, vol. 31, issue 2, pp. 636-655, 2012. https://doi.org/10.1108/03321641211 200626

[27] IEC 909-4, Short-Circuit Currents in ThreePhase a.c. Systems. Examples for the Calculation of Short-Circuit Currents, 2000.

[28] D.F.D. Carvalho, and C.J.A. Bastos-Filho, "Clan particle swarm optimization," International Journal of Intelligent Computing and Cybernetics, vol. 2, issue 2, pp. 197-227, $2009 . \quad$ https://doi.org/10.1108/175637809 10959875

[29] Y. Yao, Y. Wang, L. Xing, and H. Xu, "An optimization method of technological processes to complex products using knowledge-based genetic algorithm," Journal of Knowledge Management, vol. 19, issue 1, pp. 82-94, 2015. https://doi.org/10.1108/JKM-11-2014-0454

[30] J. Ababneh, "Greedy particle swarm and biogeography-based optimization algorithm," International Journal of Intelligent Computing and Cybernetics, vol. 8, issue 1, pp. 28-49, 2015. https://doi.org/10.1108/IJICC-01-20140003

[31] A.K. Rath, D.R. Parhi, H.C. Das, P.B. Kumar, M.K. Muni, and K. Salony, "Path optimization for navigation of a humanoid robot using hybridized fuzzy-genetic algorithm," International Journal of Intelligent Unmanned Systems, vol. 7, issue 3, pp. 112-119, 2019. https://doi.org/10.1108/IJIUS-11-2018-0032

[32] H. Hedayati, S.A. Nabaviniaki, and A. Akbarimajd, "A method for placement of DG units in distribution networks," IEEE 
Transactions on Power Delivery, vol. 23, issue 3, pp. 1620-1628, 2008.

[33] D. Das, "A fuzzy multiobjective approach for network reconfiguration of distribution systems," IEEE Transactions on Power Delivery, vol. 21, issue 1, pp. 202-209, 2006.

[34] H. Falaghi, M.R. Haghifam, and C. Singh, "Ant colony optimization-based method for placement of sectionalizing switches in distribution networks using a fuzzy multiobjective approach," IEEE Transactions on Power Delivery, vol. 24, issue 1, pp. 268276, 2009.

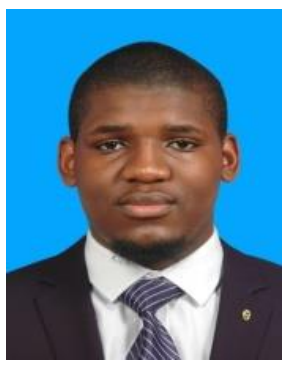

\section{Chikomborero}

Shambare

received his BEng in Electrical Engineering and its Automation from TieDao University, China in 2017 and completed his MEng in Electrical and Electronic Engineering Science from the University of Johannesburg, South Africa in 2020.

His research interests include Machine Learning, Optimization and Smart Grids.

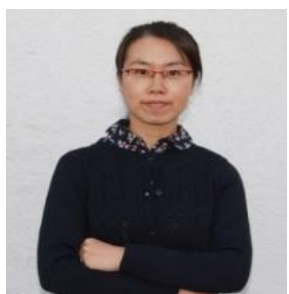

Prof. Yanxia Sun received her joint qualification: DTech in Electrical Engineering at Tshwane University of Technology, South Africa and PhD in Computer Science at University Paris-EST, France in 2012. Currently she is serving as an Associate Professor at the University of Johannesburg, South Africa. She has more than 10 years teaching and research experience. She is an IEEE senior member. Her research interests include control systems, nonlinear dynamics, optimization and renewable energy.

Dr 'Ayo IMORU received his MSc degree in Electrical Engineering at Delft University of Technology, The Netherlands in 2010 and his Doctoral degree in Electrical Engineering from Tshwane University of Technology, Pretoria, South Africa in 2017. He is a recipient of many scholarly prizes and presentation awards. Dr IMORU has over 15 years of lecturing and industrial experience in both Africa and Europe. Dr IMORU is presently a Senior Lecturer at Electrical \& Computer Engineering Department in University of Namibia (JEDS Campus), Ongwediva, Namibia. He is a senior member of IEEE and a member IAENG, NSBE, SPE as well as a registered engineer in South Africa (ECSA), Nigeria (COREN) and the Netherlands (Ir.). He has authored and co-authored about 25 publications in reputable journals, book chapters and conferences. His research interests include electrical machines and drives, fault diagnosis and monitoring, (Al, $M L \& D L)$, and Signal processing applications. 